\title{
The impact of leopards (Panthera pardus) on livestock losses and human injuries in a human-use landscape in Maharashtra, India
}

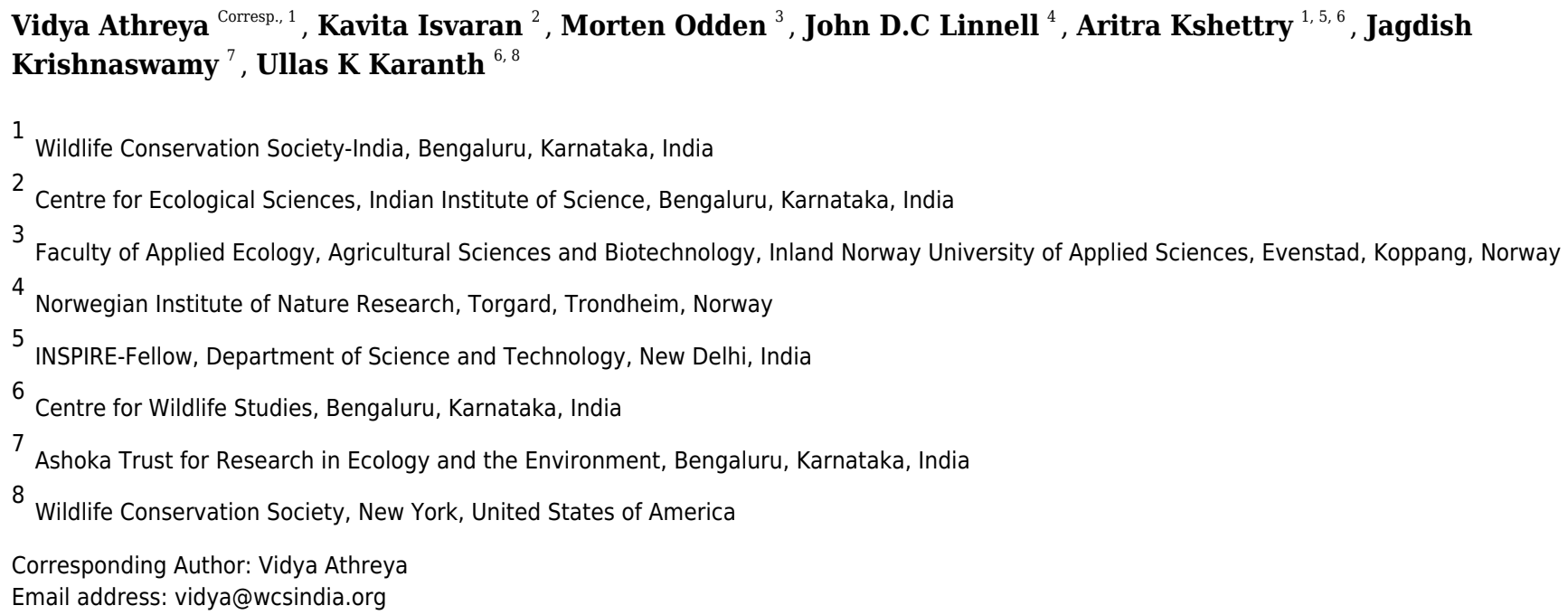

There are many ways in which large carnivores and humans interact in shared spaces. In this study we provide insights into human - leopard relationships in an entirely modified, human-dominated landscape inhabited by dense populations of humans ( 266 per $\mathrm{km}^{2}$ ), their livestock (162 per $\mathrm{km}^{2}$ ) and relatively high densities of large predators (10 per 100 $\mathrm{km}^{2}$ ). No human deaths were recorded, livestock losses to leopards numbered only 0.45 per $\mathrm{km}^{2}$ per year (averaged over three years) despite the almost complete dependency of leopards on domestic animals as prey. Predation was not the major cause of livestock mortality as diseases and natural causes caused higher losses $(80 \%$ of self-reported losses). We also found that ineffective night time protection and the presence of domestic dogs increased the probability of a farmer facing leopard attacks on livestock. Resident farmers faced much lower livestock losses to leopard predation in contrast to the migratory shepherds who reported much higher losses, but rarely availed of the government compensation schemes. We recommend that local wildlife managers continue to shift from reactive measures such as leopard captures after livestock attacks to proactive measures such as focusing on effective livestock protection and informing the affected communities about safety measures to be taken where leopards occur in rural landscapes. The natural causes of livestock deaths due do diseases may be better prevented by involving animal husbandry department for timely vaccinations and 
treatment. 
1 The impact of leopards (Panthera pardus) on livestock losses and human injuries in a human-

2 use landscape in Maharashtra, India

3

4

5 Vidya Athreya ${ }^{1}$, Kavita Isvaran ${ }^{2}$, Morten Odden ${ }^{3}$, John D.C. Linnell ${ }^{4}$, Aritra Kshettry ${ }^{1,5,8}$,

6 Jagdish Krishnaswamy6, Ullas K. Karanth,8

$7 \quad{ }^{1}$ Wildlife Conservation Society-India, Bengaluru, Karnataka, India

$8 \quad{ }^{2}$ Centre for Ecological Science, Indian Institute of Science, Bengaluru. Karnataka India.

$9 \quad{ }^{3}$ Faculty of Applied Ecology, Agricultural Sciences and Biotechnology, Inland Norway

10 University of Applied Sciences, Evenstad, Koppang, Norway.

$11{ }^{4}$ Norwegian Institute for Nature Research, Torgard, Trondheim, Norway.

12 5INSPIRE-Fellow, Department of Science and Technology, New Delhi, India

$13{ }^{6}$ Ashoka Trust for Research in Ecology and the Environment, Bengaluru, Karnataka. India.

$14 \quad{ }^{7}$ Wildlife Conservation Society, New York

15

$16 \quad{ }^{8}$ Centre for Wildlife Studies, Bengaluru, Karnataka, India

17

18 1. Corresponding Author:

19 2. Vidya Athreya

20 3. 551, 7th Main Road, Rajiv Gandhi Nagar, 2nd Phase. Kodigehalli, Bengaluru - 560097.

21 Karnataka, India.

22 Email address: vidya@wcsindia.org

\section{Abstract}


25 There are many ways in which large carnivores and humans interact in shared spaces.

26 In this study we provide insights into human - leopard relationships in an entirely

27 modified, human-dominated landscape inhabited by dense populations of humans (266

28 per $\left.\mathrm{km}^{2}\right)$, their livestock (162 per $\left.\mathrm{km}^{2}\right)$ and relatively high densities of large predators

29 (10 per $\left.100 \mathrm{~km}^{2}\right)$.

30 No human deaths were recorded, livestock losses to leopards numbered only 0.45 per

$31 \mathrm{~km}^{2}$ per year (averaged over three years) despite the almost complete dependency of

32 leopards on domestic animals as prey. Predation was not the major cause of livestock

33 mortality as diseases and natural causes caused higher losses (80\% of self-reported

34 losses). We also found that ineffective night time protection and the presence of

35 domestic dogs increased the probability of a farmer facing leopard attacks on livestock.

36 Resident farmers faced much lower livestock losses to leopard predation in contrast to

37 the migratory shepherds who reported much higher losses, but rarely availed of the 38 government compensation schemes.

39 We recommend that local wildlife managers continue to shift from reactive measures 40 such as leopard captures after livestock attacks to proactive measures such as focusing 41 on effective livestock protection and informing the affected communities about safety 42 measures to be taken where leopards occur in rural landscapes. The natural causes of 43 livestock deaths due do diseases may be better prevented by involving animal

44 husbandry department for timely vaccinations and treatment. 


\section{INTRODUCTION}

50 Conflicts between humans and large felids have been at the centre of attention in conservation because of the impact these threatened species have on the lives and

52 livelihoods of local people (Treves \& Karanth, 2003; Inskip \& Zimmermann, 2009;

53 Ripple et al., 2014), as well as the decline of wild felid populations which can occur due

54 to retaliatory killings (Inskip et al., 2014). Livestock depredation, resulting in real or

55 perceived economic losses to individual farmers, is the most common cause of human-

56 large felid conflict (Ogada et al., 2003; Katel, Pradhan \& Schmidt-Vogt, 2014; Peña-

57 Mondragón et al., 2017; Suryawanshi et al., 2017) although some species of large felids

58 are also associated with attacks on humans (Athreya et al., 2011; Kshettry, Vaidyanathan

59 \& Athreya, 2017; Packer et al., 2019). The prevention and mitigation of conflicts is a

60 challenging issue not only because of its urgency as many large felids are threatened,

61 but solutions have to take into account complex and locally dependent social and

62 cultural aspects (Barlow et al., 2010; Dickman, 2010; Redpath et al., 2013).

63

64 There is increasing evidence that poor livestock protection practices, sometimes in combination with low wild prey density, lead to livestock depredation by many individual large felids within a population (Athreya et al., 2014; Shehzad et al., 2014;

67 Suryawanshi et al., 2017; Kshettry, Vaidyanathan \& Athreya, 2018). Most of the

68 information on livestock depredation by large felids in tropical areas are from in, or

69 around, protected areas (Patterson et al., 2004; Harihar, Pandav \& Goyal, 2011;

70 Khorozyan et al., 2015) where livestock are only an alternative prey. However, a number

71 of recent studies have revealed the ability of some large carnivore species to persist in

72 human-dominated landscapes (Bhatia et al., 2013; Ripple et al., 2014; Kshettry et al.,

73 2017). In such cases, predators may heavily depend on anthropogenic food resources, 
74 such as domestic animals like dogs, livestock and garbage (Gehrt, Riley \& Cypher, 2010;

75 Athreya et al., 2014; Kshettry et al., 2018). In India, reproducing populations of some

76 large carnivores species such as wolves Canis lupus (Jhala \& Giles, 1991), Asiatic lions

77 Panthera leo (Banerjee et al., 2013), striped hyaenas Hyaena hyaena (Singh, Gopalaswamy

78 \& Karanth, 2010) and leopards Panthera pardus (Athreya et al., 2013), all of which are

79 capable of attacking livestock and humans, inhabit human-dominated landscapes with

80 dense human populations. This increased spatial overlap between large carnivores and

81 people poses a challenge to conserve them in a country with an average of more than

82380 people $/ \mathrm{km}^{2}$ (Census of India 2011).

83

84 Recent research within the field of human-wildlife conflicts has been increasingly

85 incorporating social science perspectives (e.g. Dickman 2010). These new perspectives

86 have tried to differentiate between the negative impacts that wildlife can have on

87 people (i.e. negative interactions between people and wildlife) from true conflicts that

88 people have about wildlife (i.e. negative interactions between different groups of people

89 about the way wildlife is managed) (Redpath et al., 2013). The social science

90 perspectives have also underlined how much of the substance of a human-wildlife

91 conflict can be perceptional and may be only loosely related to actual degree of

92 economic or material impact (Dickman et al., 2014). The implication is that while there is

93 a need to carefully investigate each of the different aspects of complex human-wildlife

94 interactions, there is also a need to integrate the different human perceptions when

95 deriving management recommendations. In this paper, economic losses arising due to

96 shared spaces between people and carnivores are termed 'impacts' whereas hidden

97 differences of opinions and agendas between groups of people is termed as conflict

98 (Redpath et al., 2013). 
100 Indian wildlife laws prohibit the killing of wild carnivores such as leopards and hyenas

101 (Anon 1972) and the rural communities are largely accepting of their presence (Sekar,

102 2011; Treves \& Bruskotter, 2014). However, there are many examples where local

103 people either illegally kill large carnivores associated with conflicts or put pressure on

104 wildlife management authorities to remove (translocate) animals from their

105 neighbourhood (Athreya et al., 2011). In these contexts, it is clear that there is a need for

106 robust knowledge of carnivore ecology and objective assessments of their impacts on

107 local livelihoods in a human-dominated landscape to guide effective conservation

108 efforts. This is especially true when misguided reactions, such as translocation, can have

109 potentially unforeseen negative effects such as increased attacks on humans by the

110 carnivores near the sites of release (Athreya et al., 2011). Unfortunately, there is very

111 little such knowledge available, as wildlife research in India has almost exclusively been

112 focused on protected areas (Ghosal et al., 2013). In this study, the levels of impact

113 associated with leopards in a largely rural, agricultural landscape with little wild prey,

114 but supporting high densities of domestic animals and humans was quantitatively

115 assessed. Specifically, we asked the following questions (i) what were the livestock

116 losses that people faced in the area due to leopard depredation, (ii) what factors

117 predicted livestock attacked by leopards, (iii) is compensation as a procedure evenly

118 spread among the different groups of people who report losses?

METHODS

\section{Study Area}

122 The study was carried out in Akole taluka (or county) of Ahmednagar district, located

123 in the western part of Maharashtra State, India (Figure 1). Approximately $80 \%$ of the

124 human population in Ahmednagar district is rural and the major crops grown in the

125 area are sugarcane, millet, and vegetables. Annual rainfall is highly seasonal, and can 
126 vary from 1000 to $2000 \mathrm{~mm}$, although most farmers have access to irrigation from the

127 river flowing through the valley and from percolation wells widely distributed across

128 the landscape. Akole town had a human population of about 20,000 at the time of our

129 study, while the average population density of the Ahmednagar district is 266

130 people $/ \mathrm{km}^{2}$ (Census of India 2011) and average livestock density of Ahmednagar is 162

$131 / \mathrm{km}^{2}$ (https://ahd.maharashtra.gov.in/pdf/livestock\%20census/livestock_census_19th_2012.pdf

132 accessed on September 2019). Apart from the high density of various types of livestock,

133 the density of domestic dogs which are important food resources for leopards (Athreya

134 et al. 2014) is also high at $24 / \mathrm{km}^{2}$. Dogs could be feral or owned but even in the latter

135 case, they are usually free roaming in the day time returning to the homes in the night.

137 The wild carnivores that are resident in the study area are leopard, striped hyaena,

138 golden jackal (Canis aureus), Indian fox (Vulpes bengalensis), jungle cat (Felis chaus) and

139 rusty spotted cat (Prionailurus rubiginosus) (Athreya et al., 2013) and no wild ungulate

140 species occur. The density of leopards and hyaenas is recorded at five adults of each

141 species per $100 \mathrm{~km}^{2}$ (Athreya et al., 2013). Many groups of people live in this landscape,

142 the numerically dominant group in the irrigated valley is of resident farmers who own

143 both land and livestock. Migratory shepherds, who are a pastoral group, arrive each

144 dry season (September to May) with their large herds of sheep and goats to pasture on

145 the post-harvest crop residues in fields, a practice encouraged by the landowners who

146 benefit from organic manure deposited by the animals.

148 The study was conducted in a $647 \mathrm{~km}^{2}$ area of the wider landscape surrounding the 179

$149 \mathrm{~km}^{2}$ intensive study area described in Athreya et al., (Athreya et al., 2013, 2014) which

150 centered around the town of Akole. The nearest wildlife reserve is the Kalsubai 
151 Harishchandragarh Wildlife Sanctuary $\left(299 \mathrm{~km}^{2}\right)$ which is $18 \mathrm{~km}$ away from the western

152 edge of the study area (Figure 1).

153

154 Oral consent was obtained from the farmers who were interviewed, the reasons for

155 collecting the information was provided to them and their identities were not recorded.

156 All the necessary permissions to carry out the study were obtained from the

157 Maharashtra Forest Department, the government agency responsible for protection and

158 management of all wildlife on public and private lands in the state

160 Information on livestock losses

161 Official information on the reported number of leopard encounters with humans

162 leading to injuries and claims filed for livestock attacks caused by leopards were

163 obtained from the Maharashtra Forest Department. Based on this information, three

164 different groups of people were interviewed to obtain different kinds of information.

165 (i) Residents of randomly chosen households "random households" within the

166 intensive study area were interviewed to assess the level of under-reporting of livestock

167 losses. They were chosen by dividing the entire study area into grids where all houses

168 were marked and numbered using Google Earth and one house was chosen from each

169 grid using a random number generator. We enquired about the number of domestic

170 animals they owned and if the farmers had applied for livestock compensation in the

171 last five years. Information on livestock losses over five years was obtained because the

172 number of losses in one year was too few to provide meaningful information. If they

173 had not applied for compensation, they were asked to list the reasons.

174

175 (ii) People who had lost livestock recently (in the three years between 2006 and 2009)

176 and had filed for compensation and henceforth termed as "compensation claimants"

177 were interviewed to assess the extent of their losses and the circumstances in which 
178 their livestock was lost to leopards. The farmers in this group were spread over a larger

179 landscape that surrounded the intensive study area. A wider area was sampled in order

180 to provide access to a large enough sample for statistical analysis. Information such as

181 the species, number of domestic animals owned and lost in one year, details of the

182 attack such as location (in cattle sheds, in the open, or while grazing), and location of

183 the feeding area of the animal at night (stall fed or free ranging) were obtained during

184 the interview. The quality of livestock sheds was assessed by visiting the shed where

185 the livestock were kept at night. If the sheds had an opening through which leopards

186 could get inside, or if they were fragile (made of sticks which a leopard could push

187 aside) then the quality of protection was noted as vulnerable and if the shed was

188 completely sealed it was noted as predator-resistant.

189

190 (iii) "Migratory shepherds" who use the valley in the dry season and are accompanied

191 by extremely large herds of sheep and goats face livestock losses to carnivores

192 (Agarwala et al., 2010). Information on their domestic animal holdings, the total

193 livestock mortality in the past year and all the reasons for mortality were requested.

195 All interviews were semi-structured and were conducted between September 2007 and

196 September 2009. A local farmer who was part of the team was present during the

197 interviews to increase acceptance towards the research team among the locals.

199 Analysis

200 We used Generalized Linear models with a binomial error structure and our 201 inferences were based on model selection using an information theoretic approach

202 (Burnham \& Anderson, 2002; Johnson \& Omland, 2004) to examine the following 203 questions; 
205 (i) We assessed the risk of small stock (almost always goats) versus large stock (calf)

206 being attacked by leopards. Each compensation claimant household that faced a

207 livestock attack was considered as a data point, the proportion of the species attacked

208 per household was considered as the response variable and the species of livestock

209 (goat or calf) was considered as the predictor variable. These two groups of animals

210 were chosen because initial analysis indicated that they were mainly predated upon by

211 leopards compared to other species.

212

213 (ii) We wanted to assess what variables influenced whether a household would face a

214 livestock predation event by leopards. A predation attempt was considered as the

215 response variable (with a binomial error structure) and the independent covariates

216 were whether the household owned a dog, the number of goats, the number of other

217 livestock apart from goats, and the quality of livestock protection. In this analysis, data

218 from both the "compensation claimants" and the "random households" was used.

219

220 All the covariates that were included in the competing models were based on a priori

221 knowledge and hypotheses. The best model was chosen based on the Akaike

222 Information Criterion (AIC) and the model with the smallest AIC was regarded as the

223 best approximating model. In the analyses, no single best model ( $\triangle \mathrm{AIC}>10$ from the

224 next model) was identified. Therefore, inferences were based on multiple models. In

225 such cases Akaike weights (the weight of a given model relative to other models in the

226 candidate set of models) were calculated for all models to obtain the model averaged

227 parameter estimates and confidence intervals (Burnham \& Anderson, 2002). The

228 statistical software R 2010 (version 2.11.0; R development Core Team; http//www.R-

229 project.org) was used for all the analyses. 


\section{RESULTS}

\section{Extent of livestock losses}

233 A total of 337 compensation entries of livestock depredation by leopards was reported

234 to the Forest Department between April 2006 and February 2009 over an area of $647 \mathrm{~km}^{2}$

235 (Figure 2). The total number of livestock reported as killed by leopards as per the

236 compensation records within the $179 \mathrm{~km}^{2}$ intensive study area over a three-year period

237 was 242 livestock (165 goats, 61 calves, 13 sheep and 3 adult cows from a total of 224

238 households). This implies an average of 81 livestock killed each year in a landscape (or

23945 per year per $100 \mathrm{~km}^{2}$ ) with a leopard and hyaena density of 10 adults per $100 \mathrm{~km}^{2}$

240 and a very high density of domestic animals (16200 heads per $100 \mathrm{~km}^{2}$ ). The maximum

241 number of livestock killed during one incident was 4 (reported from three households).

242

243 Despite the high density of humans and the relatively high density of leopards, no

244 human had been killed by leopards during living memory and accidental attacks

245 resulting in injury were rare in the intensive study area. During the study period (2007 -

246 2009), a boy was injured while he was cycling on a path flanked by high grass in which

247 a leopard was sitting. The leopard clawed the boy's leg but did not follow the boy even

248 though the boy was alone. In addition, just after our field work ended, in April 2009, a

249 couple was knocked off their motorbike by a leopard that was trying to cross the road at

250 the same time their bike drove past. Two more men were injured in October 2009 when

251 they were driving their motorbike at night. In this case, two leopards jumped on the

252 motorbike, bit the leg of one person and ran off into the sugarcane fields. However, it

253 was learnt later that this attack followed a provocation where another person had

254 chased one of the leopards (both were GPS-collared by us) in a jeep for nearly $500 \mathrm{~m}$. 255

256 The results indicate that both sets of farmers, 'compensation claimants' and 'random 
257 households', owned similar numbers of livestock ( $\mathrm{t}$-test, $\mathrm{p}=0.145$ ) (Table 1 ). The average

258 number of goats were 2.9 per household (range $=0-40$ ) and calves were 0.9 per

259 household (range $=0-8$ ) whereas buffaloes and sheep occurred in smaller numbers

260 (Athreya et al., 2014).

261

262 In the five-year period prior to the interviews, the 77 random households that we 263 obtained information from reported losing $1 \%$ of their livestock holdings (from a total 264 of 517) to leopards and $9 \%$ to other causes of mortality. Their losses to leopard 265 depredation were few; no buffalos, no adult cows, no calves nor sheep were killed by 266 leopards in five years with only three individuals from a total stock of 224 goats killed 267 by leopards in the five-year period. The most common causes of livestock mortality of 268 the "random households" were illness and natural causes of death (Figure 3). The only 269 exception was for domestic dogs, where leopard attacks were by far the dominant cause 270 of death (Figure 3).

271

272 In the case of the "compensation claimants" in the wider landscape, 134 of the 273 households we surveyed owned a total of 869 livestock. They reported $22 \%$ of a total of 274480 goats and $20 \%$ of a total of 80 calves dying due to leopard predation in one year. 275 Among the compensation claimants who lost livestock due to leopard attacks, the 276 probability of a goat being attacked was twice that of a calf being attacked (GLM;

277 probability of a goat being attacked: mean $=0.364 ; 95 \% \mathrm{CI}=0.148-0.650$; probability of a 278 calf being attacked: mean $=0.176 ; 95 \% \mathrm{CI}=0.106-0.266)$. The 31 "migratory shepherds" 279 owned a total of 4991 sheep and goats of which $813(16 \%)$ had died in the year prior to 280 the interview. Leopards accounted for $12 \%$ of the 813 livestock deaths, the remaining 281 occurring due to natural causes.

282

283 Patterns of livestock losses 
284

285

286

287

288

289

290

291

292

293

294

295

296

297

298

299

300

301

302

303

304

305

306

307

308

309

310

From the random households, $75 \%$ of the farmers stall-fed their livestock, $18 \%$ took them out to graze, and $7 \%$ did both ( $\mathrm{N}=68$ provided responses to this question).

Seventy-six percent of the random households $(\mathrm{N}=68$ provided responses) protected their smaller livestock in leopard-resistant sheds or had people sleeping near the livestock at night (a traditional method of protecting their livestock), while the remaining $24 \%$ of the respondents did not have leopard-proof sheds. Dogs are usually not protected and are almost always left loose outside the houses in the night, although this was not quantified.

Information from the compensation claimants indicates that most leopard attacks on livestock took place during the night (83\%; 103 farmers responded to this question), and all nighttime attacks occurred in the residential compound of the farmers (Table 2). The proximity of leopard attacks to the house also allowed the farmers to intervene and in $55 \%$ (of the 94 farmers who responded to this question) of the cases the domestic animal was retrieved. This was done for two reasons, (i) in an attempt to save the animal's life, or (ii) if it was dead, they required the carcass as evidence to file for compensation from the Forest Department. In none of these cases was the farmer attacked by the leopard which is likely to have been in the vicinity.

Our analysis (Table 3) indicates that the important predictors of a livestock predation by leopards are the presence of dogs and the quality of livestock protection, that is, livestock attacks by leopards were more likely if dogs were present in the household and if the livestock protection enclosure was not predator-resistant.

Among the people who had predator-resistant sheds and yet lost livestock, it was due to reasons such as delaying taking the goats into the shed in the evening or failing to put the livestock inside the shed for that night. Furthermore, the analysis also shows 
311 that although the average number of goats was higher ( 5.05 goats; range $=0$ to 65 ) in

312 houses that were visited by leopards to take livestock than in houses ( 2.9 goats; range $=$

3130 to 40) which did not face livestock damage due to leopards, model averaged

314 coefficients (Table 4) provide poor evidence for an effect of the number of goats on the

315 probability of livestock predation by leopards.

316

317 Compensation payment for livestock losses

318 Over a five-year period, eight of the 77 random households lost their livestock to

319 leopards of which five households did not apply for compensation. The reasons why

320 they did not apply for compensation included, (1) they did not know how to file the

321 complaint, (2) compensation was rarely provided in time, (3) the amount paid was too

322 small and many visits had to be made to the forest officer before it was given, (4) they

323 did not have time to undertake the procedure, and (5) they had reported the loss to the

324 local forest guard but he did not take action.

325

326 Sixty eight percent of the migratory shepherds lost livestock (of the 31 interviewed) to

327 leopards in the year before the interview of which $76 \%$ of the 21 shepherds (who replied

328 to the question) did not apply for compensation. Half of the shepherds who had their

329 livestock predated upon by leopards did not know they could apply for compensation

330 (10 of 21), four shepherds said they did not have the time to file the cases, and four said

331 that the procedure was too drawn-out and cumbersome. Three mentioned that filing for

332 compensation was too expensive and two said they did not get it when they had filed 333 for it.

334

335 DISCUSSION 
336 Previous ecological studies from this area have reported novel findings of a relatively

337 high density of leopards sharing the same space with a high density of humans

338 (Athreya et al., 2013, 2014) as well as the complete dependency of leopards on domestic

339 animals (livestock and dogs contributing as much as $87 \%$ of the prey biomass) as prey

340 (Athreya et al., 2014). Results from the current work indicate that the intensive study

341 area is not unique in hosting a leopard population because a much larger area of nearly

$342650 \mathrm{~km}^{2}$ also reported leopard depredation on livestock, confirming their presence

343 across a much wider landscape. Across India, leopards are known to be responsible for

344 a large number of encounters with humans leading to casualties (Kshettry et al., 2017;

345 Packer et al., 2019). However, at this study site, only three human injuries caused by

346 leopards were reported during the three-year study period. In two cases they were

347 accidental incidents and the third was a provoked response. In all cases, the animals did

348 not kill the people although it would have been easy for them to do so since there were

349 no other humans in the vicinity at the time of the incidents. No respondent could recall

350 any incident of predation on humans by leopards at the study site. This is despite close

351 interactions between humans and leopards with all the night time predation on

352 livestock occurring close to houses and half of the predated livestock being retrieved by

353 the farmers by chasing the leopards off their livestock which had been attacked. Odden

354 et al. (2014) also document using GPS telemetry how close the leopards were to

355 humans both by night and day, implying that there was a constant potential for

356 aggressive encounters between leopards and people.

358 One would expect livestock losses to be very high because of the absence of wild

359 herbivores in this landscape (Kshettry et al., 2018). However, 242 livestock killed in the

$360179 \mathrm{~km}^{2}$ intensive study area were reported as killed by leopards over three years

361 despite extremely high densities of livestock (Athreya et al., 2014), and a high density of

362 leopards (Athreya et al., 2013). For the average density of 60 houses per $\mathrm{km}^{2}$ this implied 
363 a loss of 0.45 livestock per $\mathrm{km}^{2}$ per year. The interview data also found that most of the

364 farmers protected their livestock effectively which is known to be a very important

365 factor in reducing livestock losses (Lichtenfeld, Trout \& Kisimir, 2015; Manoa \&

366 Mwaura, 2016). Therefore, the high density of livestock might not directly lead to high

367 rates of livestock depredation. It clearly also depends on other available food sources

368 (domestic dogs in this case) and how accessible the livestock is to the leopards (Athreya

369 et al., 2014). Frank et al. (Frank, Woodroffe \& Ogada, 2005) found that traditional

370 daytime and nighttime husbandry practices in Kenya are most effective at reducing

371 livestock losses to large predators, findings supported by many other studies (Meena et

372 al., 2011; Hazzah et al., 2014).

373 An interesting finding from our study was that the presence of dogs around farms

374 increased the risks of leopard predation on livestock. A common finding in other

375 studies has been that the presence of dogs, especially livestock guarding dogs, can deter

376 large predator attacks (Gehring et al., 2010; Miller et al., 2016). Dogs trained to keep

377 away predators were also used by the migratory shepherds in our study area (VA

378 personal observations) but these were largely to keep away wolves and not leopards.

379 However, the dogs used by the resident farmers were generally smaller and not bred as

380 guarding dogs and kept mostly as companions/pets. This small size, coupled with dogs

381 being an important component of leopards' diet in this landscape (Athreya et al., 2014)

382 implies that not only are they not a deterrent, but are in fact an attractant. Indirectly, the

383 presence of so many vulnerable dogs is probably one of the factors that may have led to

384 the persistence of such a dense leopard population in the study area.

385

386 In the randomly sampled households (the people who had not filed for compensation)

387 the probability of experiencing a livestock loss to leopards was seen to be small but

388 among the compensation claimants, the proportion of livestock lost to depredation was

389 relatively large. As with many other studies, our results also indicate that livestock loss 
390 to predators are a small fraction of the total losses farmers face. A review in 2010 of 18

391 studies of large cat predation found that usually no more than $5 \%$ of the total livestock

392 holding was lost to large cat depredation although in a few cases $12 \%$ loss was reported

393 (Loveridge et al., 2010). Loveridge et al. (2010) reports that livestock loss from diseases

394 and theft are usually much higher than to predation by large felids. The random

395 households in our study lost one percent of their livestock over five years to leopard

396 predation and nine percent to diseases and natural causes. In the case of migratory

397 shepherds, $12 \%$ of their livestock losses were due to predation in one year but the

398 remaining $88 \%$ was lost to other causes. Although individual losses are likely to be

399 severe for marginal farmers, conservation studies dealing with conservation conflicts

400 need to take into account losses of livestock due to all reasons, including disease etc., as

401 a measure of the impact of focal carnivore species on overall livestock losses.

402

403 This does not take away from the potential impact of leopard depredation for

404 individual, marginal farmers. As a result of these impacts India, like many countries,

405 has created a compensation system which is designed to redistribute the costs of

406 protected species from the individual farmer to wider society (Gebresenbet et al., 2017).

407 As well as representing a form of distributive justice, the philosophy (albeit rarely

408 demonstrated) is that compensation will reduce the antipathy of the affected farmers

409 towards the carnivore (Dhungana et al., 2016). However, compensation can also lead to

410 slack herding measures because the farmer expects to get compensated in case of loss

411 (Bulte \& Rondeau, 2007). For example, compensation payments were stopped in Kenya

412 because of poor financial controls and corruption (Hazzah et al., 2014), which is also

413 often a problem in India. Few of these schemes are ever monitored to assess their

414 efficacy (Nyhus et al., 2003). 
416 Our results indicate that while under-reporting of loss is very low among the resident

417 farmers (eight houses in 77 did not report losses over a period of five years), it is very

418 high among the migratory shepherds (68\% of 31 interviewed reported leopard

419 predation incidents in one year) and $76 \%$ of those that lost livestock to leopards did not

420 apply for compensation. The fact that some respondents in our study area cited the

421 procedure as cumbersome, resulting in low payment for too much effort, and did not

422 bother to apply for compensation is an indication of procedural problems with the

423 current system, especially in the case of the migratory shepherds. Large amounts of

424 government funds are spent on compensation each year by the state governments

425 without monitoring the delivery system or the effect of its intention (to make people

426 more tolerant to losses). Recently Maharashtra has improved the delivery system where

427 previous cash payments are now provided as electronic transfers directly into the

428 farmers' accounts.

429

430 However, although it can be argued that gains could be made through adjustments to

431 the procedures associated with compensation payments, it is also important to consider

432 whether greater gains could be made by moving away from paying for losses, and

433 instead move to a system of paying for, and assisting with prevention of livestock

434 losses. Compensation rates will always increase due to increasing costs of livestock but

435 if the same resources are used for proactive measures that aim at preventing a loss, it is

436 likely to result in improved longer term mitigation as well as reduce the drain on funds

437 and put the onus of protection on the farmer rather than the state agency that represents

438 the wild animal. More importantly, it will reduce losses to individual farmers, many of

439 whom are marginal and for whom livestock is an integral part of their livelihood

440 generation (Agarwala et al., 2010). Existent livestock protection practices in the

441 landscape implies that only minor modifications are required to make them effective. 
443 CONCLUSION

444

445 Carnivores are often viewed as dangerous and incompatible with human-dominated

446 landscapes. It has also been argued that there are some large cat individuals who are

447 'problem' animals and their removal will ease livestock depredations (Linnell, 2011). By

448 this definition all the leopards in our study site would be categorised as 'problem'

449 animals because they all depend at least partly on domestic animals for prey due to the

450 absence of any suitable wild prey. However, our results show that they are residing in

451 the area with an impact that is unexpectedly low considering the density of humans,

452 their livestock and leopards. Should these leopards still be termed as problem animals?

453 The term conflict is most commonly used in conservation literature while describing

454 damage incidents of livestock to predators, which are often less compared to losses due

455 to disease or illness. Conflict implies that the predator is implicated as an actor who is at

456 "fault" whereas in reality the livestock loss has occurred because of ineffective

457 protection of livestock by humans. It is important that we shift the onus of

458 responsibility to the owners of the livestock rather than on the predator who will attack

459 any herbivore/carnivore without distinguishing whether it is wild or domestic if it is

460 available. Recently several authors (Redpath et al., 2013; Davidar, 2018) have called for

461 the word "conflict" to be only used for the human-human aspect of conservation

462 conflicts, preferring to reserve the word "impact" for the material and economic effects

463 of predators on people. In our study site there were relatively few social conflicts linked

464 to the leopards (Ghosal \& Kjosavik, 2015), and impacts were relatively low and widely

465 dispersed across the human population. In many ways, the discourse could be even

466 more constructively switched away from impacts to one of a failure to completely adapt

467 to the presence of leopards (Carter \& Linnell, 2016). However, when compared to many

468 other case studies of human-large felid interactions and the associated conflicts, the

469 situation in Akole is very close to coexistence (sensu Carter \& Linnell 2016), and the 
470 required adjustments to human practices are minor. Now is certainly the time to make 471 the necessary adjustments, as it is likely to be far easier to prevent escalating impacts, 472 and potential conflicts from developing than reverse them once they have appeared 473 (Miller et al., 2016).

474

475 


\section{Role of funding source}

477 The study was funded by a Kaplan Graduate Award (Panthera), the Wildlife Conservation

478 Society, the Royal Norwegian Embassy in New Delhi, the Norwegian Institute of Nature

479 Research, the Research Council of Norway (grants 201693 and 251112) and the Asian Nature

480 Conservation Foundation. None of these institutions had a role to play in deciding the study

481 design, the logistics of field work, nor in the analysis and writing of the manuscript.

482

483 Acknowledgements

484 We would like to thank the Maharashtra Forest Department for their collaborative support to

485 this project. We would like to especially thank Mr B. Majumdar (retired Chief Wildlife Warden),

486 Mr P. Thosre (Retired Additional PCCF), Mr Saiprakash (PCCF) and Mr Phatangare (DFO

487 Wildlife Pune). The work was only possible, and even more enjoyable, due to the presence of

488 Mr Ghule who was part of our field team.

489

490

\section{Declaration of conflicting interests}

491 'The Author(s) declare(s) that there is no conflict of interest'.

492

493

\section{References}

494

495

496

497

498

499
Agarwala, M., Kumar, S., Treves, A. \& Naughton-Treves, L. (2010). Paying for wolves in Solapur, India and Wisconsin, USA: Comparing compensation rules and practice to understand the goals and politics of wolf conservation. Biol. Conserv. 143, 2945-2955.

Athreya, V., Odden, M., Linnell, J.D.C. \& Karanth, K.U. (2011). Translocation as a tool for mitigating conflict with leopards in human-dominated landscapes of India. Conserv. Biol. 25, 133-41. 
500

501

502

503

504

505

506

507

508

509

510

511

512

513

514

515

516

517

518

519

520

521

522

523

524

525

526

527

528

529

530

531

532

533

534

535

536

537

Athreya, V., Odden, M., Linnell, J.D.C., Krishnaswamy, J. \& Karanth, K.U. (2014). A cat among the dogs: leopard Panthera pardus diet in a human-dominated landscape in western Maharashtra, India. Oryx 1-7.

Athreya, V., Odden, M., Linnell, J.D.C., Krishnaswamy, J. \& Karanth, U. (2013). Big cats in our backyards: persistence of large carnivores in a human dominated landscape in India. PLoS One 8, e57872.

Banerjee, K., Jhala, Y. V., Chauhan, K.S. \& Dave, C. V. (2013). Living with Lions: The Economics of Coexistence in the Gir Forests, India. PLoS One 8, e49457.

Barlow, A.C.D., Greenwood, C.J., Ahmad, I.U. \& Smith, J.L.D. (2010). Use of an action-selection framework for human-carnivore conflict in the Bangladesh Sundarbans. Conserv. Biol. 24, 1338-47.

Bhatia, S., Athreya, V., Grenyer, R. \& MacDonald, D.W. (2013). Understanding the role of representations of human-leopard conflict in Mumbai through media-content analysis. Conserv. Biol. 27, 588-94.

Bulte, E. \& Rondeau, D. (2007). Compensation for wildlife damages: Habitat conversion, species preservation and local welfare. J. Environ. Econ. Manage. 54, 311-322.

Burnham, K.P. \& Anderson, D.R. (2002). Model Selection and Multimodel Inference: A Practical Information-Theoretic Approach. Springer Science \& Business Media.

Carter, N.H. \& Linnell, J.D.C. (2016). Co-Adaptation Is Key to Coexisting with Large Carnivores. Trends Ecol. Evol. xx, 4-7.

Davidar, P. (2018). The term human-wildlife conflict creates more problems than it resolves: better labels should be considered. J. Threat. Taxa 10, 12082-12085.

Dhungana, R., Savini, T., Karki, J.B. \& Bumrungsri, S. (2016). Mitigating human-tiger conflict: an assessment of compensation payments and tiger removals in Chitwan National Park, Nepal. Trop. Conserv. Sci. 9, 776-787.

Dickman, a. J. (2010). Complexities of conflict: The importance of considering social factors for effectively resolving human-wildlife conflict. Anim. Conserv. 13, 458-466.

Dickman, A.J., Hazzah, L., Carbone, C. \& Durant, S.M. (2014). Carnivores, culture and 'contagious conflict': Multiple factors influence perceived problems with carnivores in Tanzania's Ruaha landscape. Biol. Conserv. 178, 19-27.

Frank, L.G., Woodroffe, R. \& Ogada, M. (2005). Peoople and predators in Laikipia District, Kenya. In People and Wildlife: Conflict or coexistence.

Gebresenbet, F., Baraki, B., Yirga, G., Sillero-Zubiri, C. \& Bauer, H. (2017). A culture of tolerance: coexisting with large carnivores in the Kafa Highlands, Ethiopia. Oryx 1-10.

Gehring, T.M., VerCauteren, K.C., Provost, M.L. \& Cellar, A.C. (2010). Utility of livestockprotection dogs for deterring wildlife from cattle farms. Wildl. Res. 37, 715.

Gehrt, S.D., Riley, S.P.D. \& Cypher, B.L. (2010). Urban Carnivores: Ecology, Conflict, and Conservation. JHU Press. 
538 Ghosal, S., Athreya, V.R., Linnell, J.D.C. \& Vedeld, P.O. (2013). An ontological crisis? A review 539 of large felid conservation in India. Biodivers. Conserv. 22, 2665-2681.

540 Ghosal, S. \& Kjosavik, D.J. (2015). Living with Leopards: Negotiating Morality and Modernity in Western India. Soc. Nat. Resour. 1-16.

542

543

544

545

546

547

548

549

550

551

552

553

554

555

556

557

558

559

560

561

562

563

564

565

566

567

568

569

570

571

572

573

574

575

Harihar, A., Pandav, B. \& Goyal, S.P. (2011). Responses of leopard Panthera pardus to the recovery of a tiger Panthera tigris population. J. Appl. Ecol. 48, 806-814.

Hazzah, L., Dolrenry, S., Naughton, L., Edwards, C.T.T., Mwebi, O., Kearney, F. \& Frank, L. (2014). Efficacy of two lion conservation programs in maasailand, kenya. Conserv. Biol. 28, 851-60.

Inskip, C., Fahad, Z., Tully, R., Roberts, T. \& MacMillan, D. (2014). Understanding carnivore killing behaviour: Exploring the motivations for tiger killing in the Sundarbans, Bangladesh. Biol. Conserv. 180, 42-50.

Inskip, C. \& Zimmermann, A. (2009). Human-felid conflict: a review of patterns and priorities worldwide. Oryx 43, 18.

Jhala, Y. \& Giles, R.H. (1991). The Status and Conservation of the Wolf in Gujarat and Rajasthan, India. Soc. Conserv. Biol. 5, 476-483.

Johnson, J.B. \& Omland, K.S. (2004). Model selection in ecology and evolution. Trends Ecol. Evol. $19,101-8$.

Katel, O.N., Pradhan, S. \& Schmidt-Vogt, D. (2014). A survey of livestock losses caused by Asiatic wild dogs, leopards and tigers, and of the impact of predation on the livelihood of farmers in Bhutan. Wildl. Res. 41, 300-310.

Khorozyan, I., Ghoddousi, A., Soofi, M. \& Waltert, M. (2015). Big cats kill more livestock when wild prey reaches a minimum threshold. Biol. Conserv. 192, 268-275.

Kshettry, A., Vaidyanathan, S. \& Athreya, V. (2017). Leopard in a tea-cup: A study of leopard habitat-use and human-leopard interactions in north-eastern India. PLoS One 12, 1-15.

Kshettry, A., Vaidyanathan, S. \& Athreya, V. (2018). Diet Selection of Leopards ( Panthera pardus ) in a Human-Use Landscape in North-Eastern India. Trop. Conserv. Sci. 11, 1-9.

Lichtenfeld, L.L., Trout, C. \& Kisimir, E.L. (2015). Evidence-based conservation: predator-proof bomas protect livestock and lions. Biodivers. Conserv. 24, 483-491.

Linnell, J.D.C. (2011). Can we separate the sinners from the scapegoats? Anim. Conserv. 14, 602603.

Loveridge, A.J., Wang, S.W., Frank, L.G. \& Seidensticker, J. (2010). People and wild felids: conservation of cats and management of conflicts. In Biology and Conservation of Wild Felids: 161-195. David Macdonald \& Andrew Loveridge (Eds.). Oxford Univerisity Press.

Manoa, D.O. \& Mwaura, F. (2016). Predator-Proof Bomas as a Tool in Mitigating HumanPredator Conflict in Loitokitok Sub-County , Amboseli Region of Kenya 28-39.

Meena, V., Jhala, Y. V, Chellam, R. \& Pathak, B. (2011). Implications of diet composition of Asiatic lions for their conservation. J. Zool. 284, 60-67.

Peer) reviewing PDF | (2019:05:38063:2:0:NEW 30 Nov 2019) 
576

577

578

579

580

581

582

583

584

585

586

587

588

589

590

591

592

593

594

595

596

597

598

599

600

601

602

603

604

605

606

607

608

609

610

611

Miller, J.R.B., Stoner, K.J., Cejtin, M.R., Meyer, T.K., Middleton, A.D. \& Schmitz, O.J. (2016). Effectiveness of contemporary techniques for reducing livestock depredations by large carnivores. Wildl. Soc. Bull. 40, 806-815.

Nyhus, P.J., Osofsky, S.A., Ferraro, P., Madden, F. \& Fischer, H. (2003). Bearing the costs of human-wildlife conflict: The challenges of compensation schemes.

Odden, M., Athreya, V., Rattan, S. \& Linnell, J.D.C. (2014). Adaptable Neighbours: Movement Patterns of GPS-Collared Leopards in Human Dominated Landscapes in India. PLoS One 9, e112044.

Ogada, M., Woodroffe, R., Oguge, N.O. \& Frank, L.G. (2003). Limiting Depredation by African Carnivores: the Role of Livestock Husbandry. Conserv. Biol. 17, 1521-1530.

Packer, C., Shivakumar, S., Athreya, V., Craft, M.E., Dhanwatey, H., Dhanwatey, P., Gurung, B., Joshi, A., Kushnir, H., Linnell, J.D.C. \& Fountain-Jones, N.M. (2019). Species-specific spatiotemporal patterns of leopard, lion and tiger attacks on humans. J. Appl. Ecol. 56, 585593.

Patterson, B.D., Kasiki, S.M., Selempo, E. \& Kays, R.W. (2004). Livestock predation by lions (Panthera leo) and other carnivores on ranches neighboring Tsavo National ParkS, Kenya. Biol. Conserv. 119, 507-516.

Peña-Mondragón, J.L., Castillo, A., Hoogesteijn, A. \& Martínez-Meyer, E. (2017). Livestock predation by jaguars Panthera onca in south-eastern Mexico: the role of local peoples' practices. Oryx 51, 254-262.

Redpath, S.M., Young, J., Evely, A., Adams, W.M., Sutherland, W.J., Whitehouse, A., Amar, A., Lambert, R.A., Linnell, J.D.C., Watt, A. \& Gutie, R.J. (2013). Understanding and managing conservation conflicts. Trends Ecol. Evol. 28, 1-10.

Ripple, W.J., Estes, J. a, Beschta, R.L., Wilmers, C.C., Ritchie, E.G., Hebblewhite, M., Berger, J., Elmhagen, B., Letnic, M., Nelson, M.P., Schmitz, O.J., Smith, D.W., Wallach, A.D. \& Wirsing, A.J. (2014). Status and ecological effects of the world's largest carnivores. Science $343,1241484$.

Sekar, N. (2011). Tolerance for the Charismatic Marauders. Economic and Political Weekly 2013.

Shehzad, W., Nawaz, M.A., Pompanon, F., Coissac, E., Riaz, T., Shah, S.A. \& Taberlet, P. (2014). Forest without prey: livestock sustain a leopard Panthera pardus population in Pakistan. Oryx 1-6.

Singh, P., Gopalaswamy, A.M. \& Karanth, K.U. (2010). Factors influencing densities of striped hyenas ( Hyaena hyaena ) in arid regions of India. J. Mammal. 91, 1152-1159.

Suryawanshi, K.R., Redpath, S.M., Bhatnagar, Y.V., Ramakrishnan, U., Chaturvedi, V., Smout, S.C. \& Mishra, C. (2017). Impact of wild prey availability on livestock predation by snow leopards. Open Sci. 4.

612 Treves, A. \& Bruskotter, J. (2014). Tolerance for Predatory Wildlife. Sci. (New York 344, 12-14.

613 Treves, A. \& Karanth, K.U. (2003). Human-Carnivore Conflict and Perspectives on Carnivore 
614 Management Worldwide. Conserv. Biol. 17, 1491-1499. 


\section{Table $\mathbf{1}$ (on next page)}

Comparison of livestock mortality between random households and compensation claimants.

The random households provided information over five years prior to the interview as their yearly losses were too few to enumerate. The compensation claimants provided information for the year prior to the interview to avoid recall bias. 
Table 1: Comparison of livestock mortality between random households and compensation 1 claimants. The random households provided information over five years prior to the interview 2 as their yearly losses were too few to enumerate. The compensation claimants on the other hand 3 provided information for the year prior to the interview.

4

5

\begin{tabular}{|l|c|c|c|c|}
\hline \multirow{2}{*}{} & \multicolumn{2}{|c|}{ Random households } & \multicolumn{2}{c|}{ Compensation claimants } \\
\hline & Owned & Leopard kills & Owned & 107 \\
\hline Goats & 224 & 3 & 480 & 2 \\
\hline Sheep & 5 & 0 & 0 & 17 \\
\hline Calves & 70 & 0 & 83 & 1 \\
\hline Adult cattle & 209 & 0 & 293 & 0 \\
\hline Buffalo & 9 & 0 & 13 & 127 \\
\hline Total & 517 & 3 & 869 & \\
\hline
\end{tabular}




\section{Table 2 (on next page)}

Time and location details of livestock attacks (number of attacks) by leopards obtained from the compensation claimants. The total number of responses we got for this question was from 103 claimants. 
Table 2: Time and location details of livestock attacks (number of attacks) by leopards obtained 1 from the compensation claimants. The total number of responses we got for this question was 2 from 103 claimants.

\begin{tabular}{|c|c|c|c|c|}
\hline & $\begin{array}{c}\text { Day time } \\
(0600-1800)\end{array}$ & $\begin{array}{l}\text { Night time } \\
(1800-0600)\end{array}$ & Do not know & Total \\
\hline Grazing & 12 & 0 & 0 & 12 \\
\hline Outside house & 1 & 78 & 0 & 79 \\
\hline Do not know & 1 & 4 & 0 & 5 \\
\hline Total & 14 & 82 & 7 & 103 \\
\hline
\end{tabular}




\section{Table 3(on next page)}

Generalised Linear Models (binomial errors) where the response variable that was modelled was the probability of a leopard attack on livestock. The data set consists of both compensation claimants as well as random households. 
Table 3: Generalised Linear Models (binomial errors) where the response variable that was 1 modelled was the probability of a leopard attack on livestock. The data set consists of both 2 compensation claimants as well as random households.

Model Deviance AICc $\triangle \mathrm{AICC} w$

Dogs present+livestock protected+dogs present: livestock 119.76

$128.03 \quad 0.00$

protected

Dogs present + livestock protected

123.04

129.21

1.17

0.15

Dogs present + number of goats + livestock protected + dogs

119.01

129.43

1.39

0.14

present: livestock protected

Dogs present + number of other livestock + number of goats +116.96

$129.55 \quad 1.52$

livestock protected + dogs present: livestock protected

Dogs present + number of other livestock + livestock

121.88

130.16

2.12

0.09

protected

Dogs present + number of goats + livestock protected

122.07

130.35

2.31

0.09

Dogs present + number of other livestock + number of goats +

131.06

3.03

0.06

livestock protected

Livestock protected

128.06

132.14

4.11

0.03

Number of goats + livestock protected

127.23

133.40

5.37

0.02

Number of other livestock + livestock protected

128.03

134.19

6.16

0.01 


\begin{tabular}{|c|c|c|c|c|}
\hline Model & Deviance & $\mathrm{AlCc}$ & $\triangle \mathrm{AICC}$ & w \\
\hline Number of other livestock + number of goats + livestock & 127.19 & 135.47 & 7.43 & 0.01 \\
\hline \multicolumn{5}{|l|}{ protected } \\
\hline Dogs present + number of goats & 191.08 & 197.25 & 69.21 & 0.00 \\
\hline Dogs present + number of other livestock + number of goats & 190.84 & 199.12 & 71.08 & 0.00 \\
\hline Dogs present & 195.85 & 199.93 & 71.90 & 0.00 \\
\hline Dogs present + number of other livestock & 195.73 & 201.89 & 73.86 & 0.00 \\
\hline Number of goats & 199.29 & 203.37 & 75.33 & 0.00 \\
\hline Number of goats + number of other livestock & 198.98 & 205.15 & 77.11 & 0.00 \\
\hline Number of other livestock & 203.15 & 207.24 & 79.20 & 0.00 \\
\hline
\end{tabular}




\section{Table 4(on next page)}

Model-averaged estimate and $95 \%$ confidence interval $(\mathrm{Cl})$ of factors affecting the chances of leopard attacks on livestock held in farmer's pens.

Interview data from both, 'compensation claimants' and 'random households' were used. The interviews were held between September 2007 and September 2009. 
Table 4. Protection related factors where the response variable modelled was the probability of a leopard attack on livestock assessed using Generalised Linear Models with binomial errors. The reported figures are: Model-averaged estimate and 95\% confidence interval (CI) of parameters representing factors affecting the chances of leopard attacks on livestock held in farmer's pens. Interview data from both, 'compensation claimants' and 'random households' were used. The interviews were held between September 2007 and September 2009.

\begin{tabular}{lccc}
\hline \multicolumn{1}{l}{ Model averaged parameters } & Coefficient & Lower $\mathrm{Cl}$ & Upper Cl \\
& & & \\
& & & \\
\hline Dogs present & 1.93 & 0.0771 & 3.79 \\
Number of livestock except goats & -0.0844 & -0.229 & 0.06 \\
Number of goats & & & 0.309 \\
Protection not effective & 0.101 & -0.107 & 5.22 \\
Dogs present : Protection not effective & 3.85 & 2.48 & 0.16 \\
\end{tabular}


Figure 1

The Ahmednagar district is shown with the study area marked as a polygon where information on livestock losses was collected from households chosen randomly. The black dots represent the households which reported livestock loss and claimed compensation

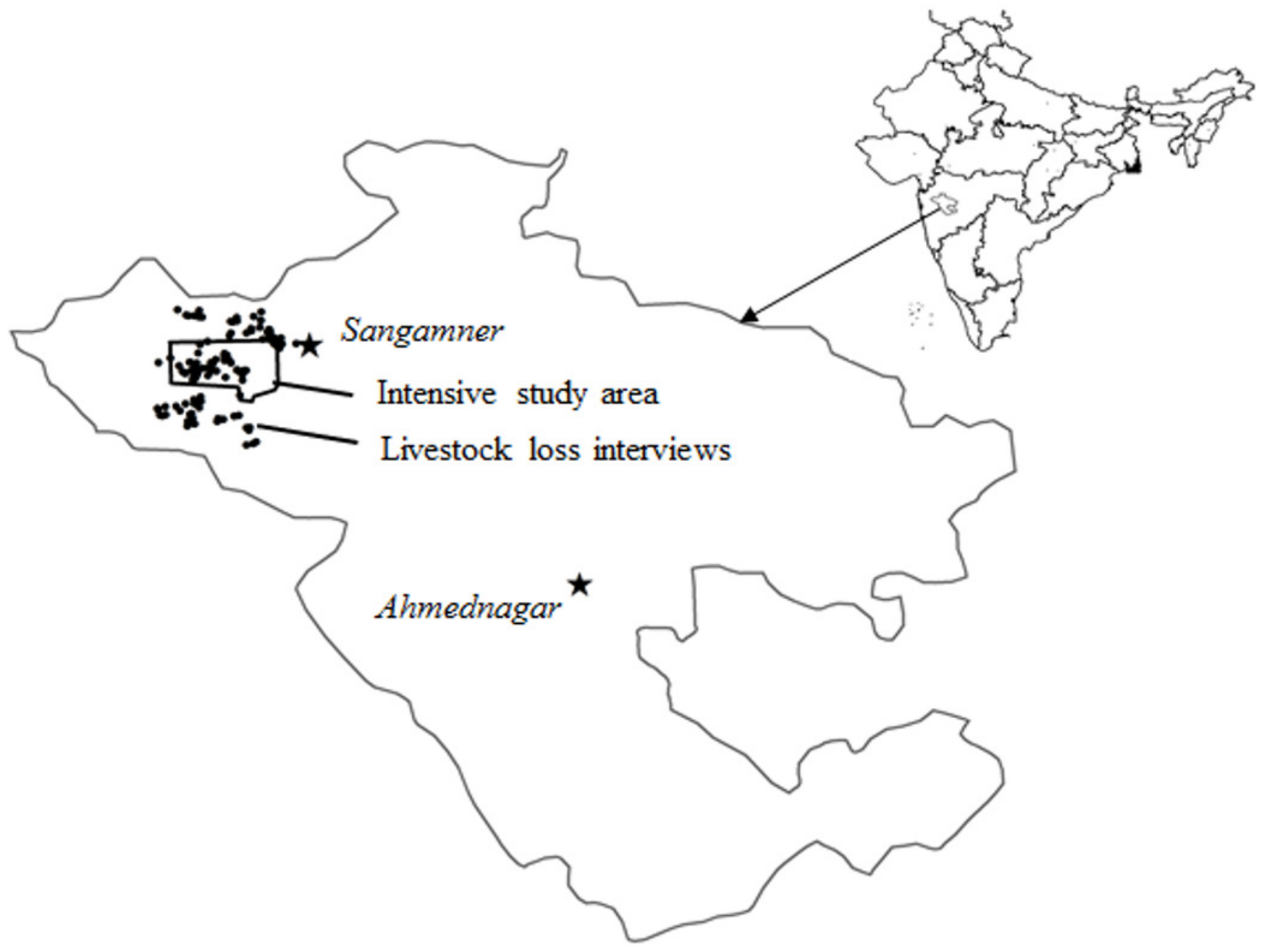


Figure 2

Seasonal distribution of the average number of livestock (with SD bars) reported preyed upon by leopards in the intensive study area $\left(179 \mathrm{~km}^{2}\right)$ between April 2006 and February 2009. The information is from Forest Department records

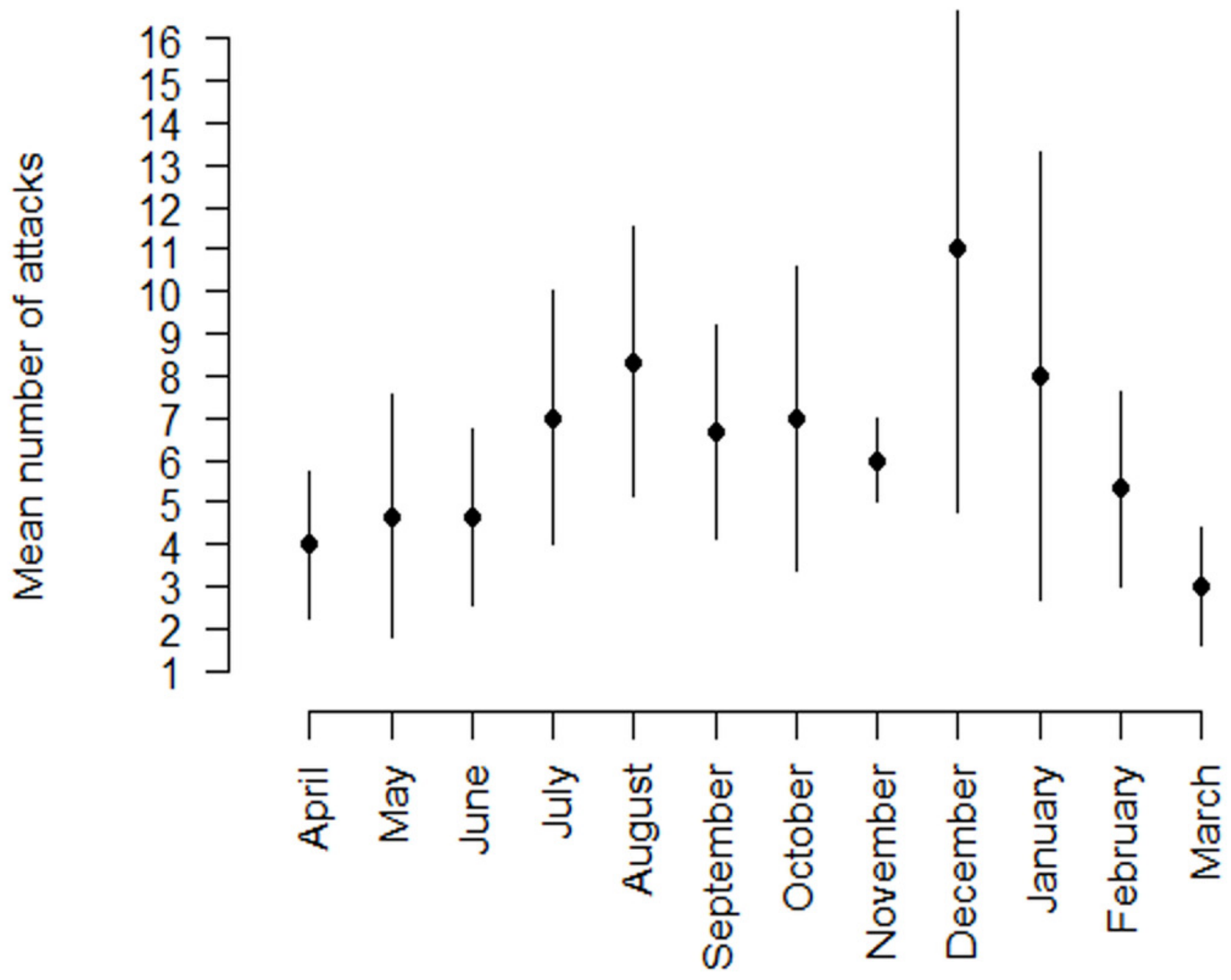


Figure 3

Causes of livestock mortality among the randomly interviewed farmers $(n=77)$ from the intensive study area of Akole over a five year period

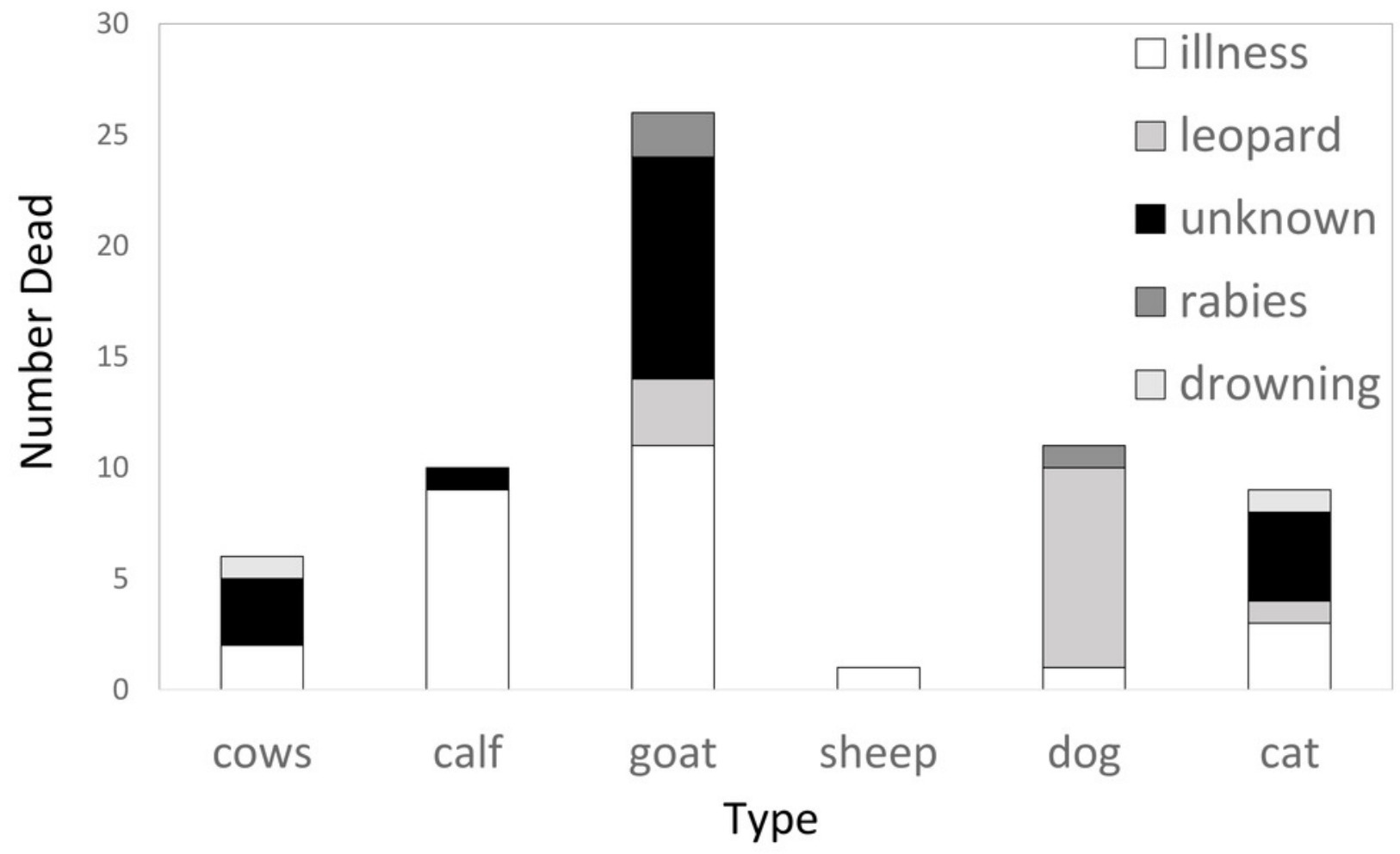

